\title{
Paleogene lake deep water sedimentary facies in the northern zone of the Chezhen Sag, Bohai Bay Basin, China
}

\author{
Zhang Yuanpei $^{1} \cdot$ Zhang Xuecai $^{3} \cdot$ Cao Haifang ${ }^{3} \cdot$ Zheng Xugang $^{3} \cdot$ Wang Jinkai $^{1,2} \cdot$ Zhang Jinliang $^{4}$
}

Received: 12 May 2021 / Accepted: 6 September 2021 / Published online: 15 September 2021

(c) The Author(s) 2021

\begin{abstract}
This study researches an important genetic type of Paleogene sublacustrine fan deposits in widely developed glutenite bodies in the northern Chezhen Sag. The Paleogene sublacustrine fans in the Bohai Bay Basin are primarily distributed in $\mathrm{Es}_{3}$ (The third member of Paleogene Shahejie Formation). There are many sedimentary types in Chezhen depression, but understanding of the reservoir is too limited to support a development strategy. Therefore, a detailed study on the core characteristics, sedimentary structure, sedimentary microfacies and reservoir properties has been completed in order to reduce uncertainty. It is confirmed that the sublacustrine fan deposits are mostly characterized by a positive cycle of upward thinning, and the base is composed of conglomerate supporting conglomerate and massive gravel sandstone, which reflect the sedimentary characteristics of traction and gravity currents. Finally, the influence of sedimentary process on properties was assessed by establishing the correlation between microfacies and reservoir physical parameters, such as porosity, permeability, detrital particle. It is revealed that the sublacustrine fan glutenite body formed in the deep depression period is interspersed with deep- to semi-deep lake source rocks. The superior source-reservoir-caprock combination is one of the most important exploration targets in the northern zone.
\end{abstract}

Keywords Chezhen Sag $\cdot$ Sedimentary facies $\cdot$ Paleogene $\cdot$ Sublacustrine fan

\section{Introduction}

The fan-shaped clastic rock mass caused by deep water gravity flow in the lake basin is defined as a sublacustrine fan (Liu and zhao 1984). Researchers usually refer to turbidite fans in deep water lake environments as sub-lake fans. Geographically, sub-lake fans can be located on steep banks, gentle banks, or deep horizontal plains and can be formed by the gravity of floods, which directly inject a current into

Wang Jinkai

wangjk@sdust.edu.cn

1 College of Earth Science and Engineering, Shandong University of Science and Technology, Qingdao 266590, China

2 Laboratory for Marine Mineral Resources, Qingdao National Laboratory for Marine Science and Technology, Qingdao 266237, China

3 Management Centre of Oil and Gas Exploration, Shengli Oilfield, SINOPEC, Dongying 257000, China

4 Faculty of Geographical Science, Beijing Normal University, Beijing 100875, China the deep water area. The fan can also be formed by the rapid accumulation of sediments in the fan delta or at the front edge of underwater alluvial fans. The granularity of the former fans is finer, whereas the granularity of the latter is often coarser (Fan 2007). Evidence indicates that the Paleogene sublacustrine fans in the northern zone of the Chezhen Sag can be divided into two or three types. Liu et al. (2003) divided sublacustrine fans into channel-type and lenticular fans according to the formation mechanism of the lacustrine turbidity currents. Turbidite reservoirs are believed to be among the most oil-bearing reservoirs, and their internal changes are controlled by many factors, such as the tectonic background, the sedimentary environment, and diagenesis (Liu et al. 2003). Generally speaking, sedimentary facies types can be divided into different types according to their genetic mechanism, seismic characteristics, sedimentary characteristics and differences in core sedimentary units (Shehata et al. 2021). They have not only broad commonalities, but also their own particularities (Haghjoue et al. 2021). Sublacustrine fans were usually classified into slump and channel types based on the sedimentary structure, or they can be divided into sublacustrine fans into non-hydro 
channelized sandy detrital flow lake fans, non-hydro channelized turbidity current lake fans, and channelized lake bottom fans according to the development degree of the fan channel (Nguidi et al. 2021; Cumberpatch et al. 2021).

Researchers have recently studied the glutenite fan in the northern zone of the Chezhen Depression. The Paleogene $\mathrm{Es}_{3}-\mathrm{Es}_{1}$ in the Chezhen Sag is divided into four three-level sequences. The study area is believed to primarily contain fan delta and nearshore subaqueous fan sedimentary facies. The Paleogene $\mathrm{Es}_{3}{ }_{3}-\mathrm{Es}_{2}{ }^{3}$ of the Chezhen Sag was further divided into the lowstand, lacustrine transgressive, and highstand system tracts. The developed sedimentary facies in each system tract have been studied (Wang et al. 2005). Peng et al. (2007) studied the sedimentary facies developed in $\mathrm{Es}_{3}{ }^{3}$ of Block C66 and believed that slump turbidite fan and sublacustrine fan deposits developed in the area (Peng et al. 2007). Xian et al. (2006) studied the sedimentary facies of Paleogene $\mathrm{Es}_{4}-\mathrm{Es}_{2}{ }^{3}$ and believed that $\mathrm{Es}_{4}{ }^{3}, \mathrm{Es}_{4}{ }_{4}, \mathrm{Es}_{3}{ }^{3}$, and $\mathrm{Es}_{3}{ }^{2}$ developed alluvial fan deposits, fan deltas and a few turbidite fans, extensive nearshore underwater fans and sublacustrine fan deposits, and nearshore submarine fans and small-scale sublacustrine fan deposits, respectively; from $\mathrm{Es}_{3}{ }^{1}$ to $\mathrm{Es}_{2}{ }^{3}$, the sedimentary facies developed nearshore submarine fans, fan deltas, and small-scale sublacustrine fan deposits (Xian 2005). Wang et al. (2006), Xian et al. (2007), and Lu et al. (2008) conducted a detailed study on the fault structure in the northern zone of the Chezhen Depression and categorized four types of fault structures: slab, shovel, stepped, and sloped. The type of fault structure is believed to significantly affect the development of sedimentary reservoirs, which in turn affect the formation of hydrocarbon accumulations (Wang and Xian 2006; Xian et al. 2007; Lu 2008).

Previously, seismic description technology was used to predict the distribution of glutenite effective reservoirs in the study area (Wang et al. 2008) using seismic high-frequency energy attenuation detection technology to predict the physical properties of the reservoir (Liu et al. 2009). Dividing glutenite reservoirs into fine stages (Wang et al. 2020) and determining a reasonable vertical development unit and effectively thin sand body and water injection (WAG)] type can effectively reduce the impact of vertical heterogeneity and significantly increase oil recovery (Wang et al. 2016). Li et al. (2008) studied the reservoir characteristics and influencing factors of the Paleogene glutenite body in the northern Chezhen zone and found low compositional and structural maturities. Intergranular and intragranular dissolved pores are the primary types of storage space. In addition, microfractures also have a storage capacity. The physical properties of the reservoir deteriorate as the burial depth increases; deep-seated pores become more developed; and accumulation, diagenesis, and abnormal pressure affect the three primary factors of the reservoir physical properties, among which the sedimentary facies zone is fundamental (Li et al. 2008). Lu et al. (2008) analyzed the Paleogene structural style in the Chezhen Sag and concluded that the structural style affected the quality of the reservoir by affecting the vertical stacking mode, scale, deposition type, and sand body structure of the glutenite body (Lu 2008). The above-mentioned literature review reveals that the fault step and slope-type structural style areas are rich in sedimentary types and are the most developed areas of favorable reservoirs; sublacustrine fans develop in the shovel-style structural area; and a single, thin layers of glutenite are a secondary favorable area. However, glutenite in plate-style structured areas has a narrow distribution and large single layer thickness with the worst reservoir quality. Based on the summary and analysis of previous studies, the deposition and reservoir research of the northern glutenite body in the Chezhen Sag has the following problems: first, the understanding of the sedimentary facies of the Paleogene sublacustrine fan in the study area is unclear, and accurately analyzing the distribution law of glutenite fans in various periods is difficult; second, the effectiveness of the reservoir in the study area is not sufficiently studied, and the lower limit of the effective reservoir physical properties and controlling factors of glutenite bodies remain unclear. These problems have severely restricted further oil and gas exploration of the glutenite body in the study area. This research systematically solves these problems, establishes an accurate deposition model and the distribution characteristics of the deposition system, and discusses the influencing factors of the sandstone physical properties, which played a prominent role in reservoir development.

\section{Overview of the study area}

The Bohai Bay Basin is located in the central area of the southeastern Eurasian Plate near the intersection of three major structural domains: the Pacific Ocean, the Tethys Ocean, and the Paleo-Asian Ocean. The superimposed composite basin within the North China Plate dates to the Mesozoic and Cenozoic (Fig. 1a). The Chezhen Sag is one of the four major subsags of the Jiyang Sag in the Bohai Bay Basin and is located in the northern part of the Jiyang Sag (Liu et al. 2013). The Chezhen Sag is composed of the Chexi, Dawangbei, and Guojuzi sub-sags. The study area is located in the central western Chezhen Sag, bounded by the Chengzikou Uplift to the north, the Yihezhuang Uplift to the south, and the Dawangbei and Chexi Sags to the east and west, respectively (Fig. 1b). 


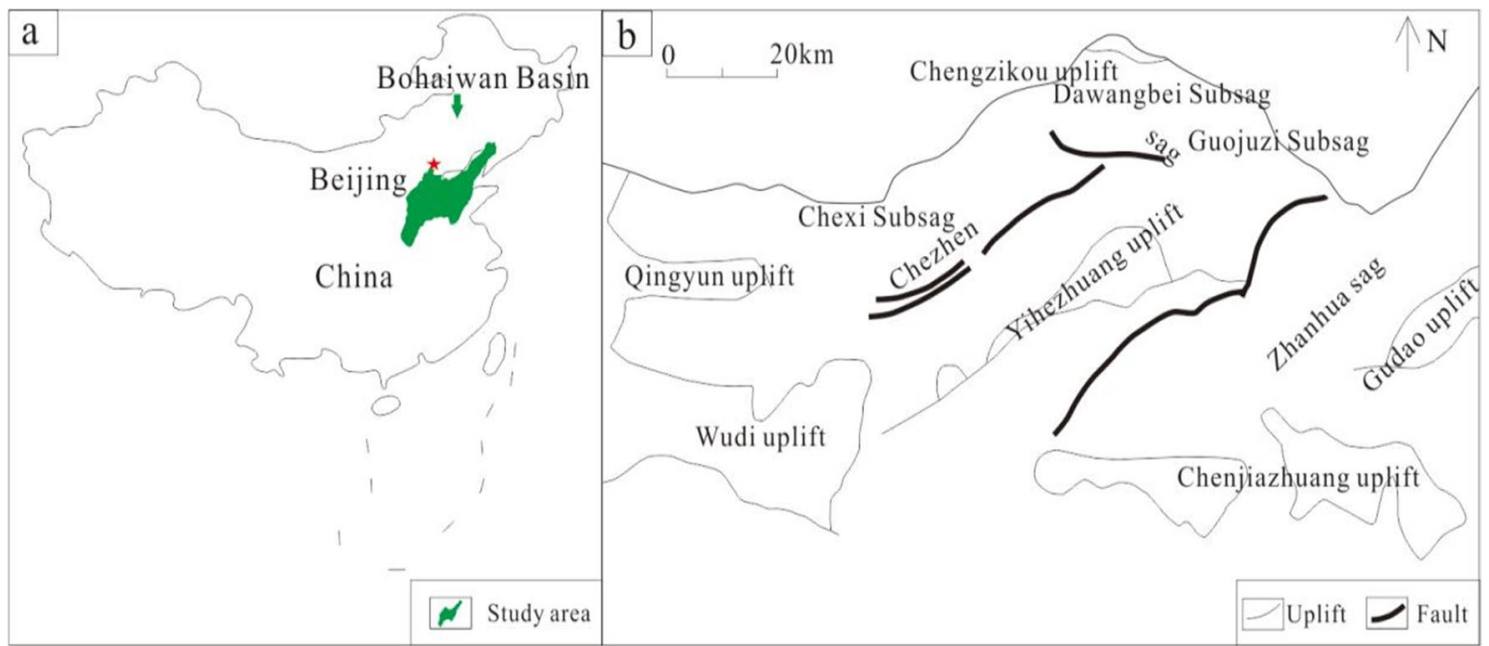

Fig. 1 Map of the study area a Location of the Bohaiwan Basin, bLocations of structures in the study area

Table 1 Statistical table of detrital particle composition of each submember of the third member of Shahejie Formation in Chezhen Sag

\begin{tabular}{llll}
\hline Horizon & $\mathrm{Es}_{3}{ }^{3}$ & $\mathrm{Es}_{3}{ }^{2}$ & $\mathrm{Es}_{3}{ }^{1}$ \\
\hline Statistical well number & 5 & 5 & 8 \\
Sample number & 23 & 23 & 30 \\
Quartz & 36.29 & 31.27 & 44.97 \\
Potassium feldspar & 4.9 & 13.57 & 14.48 \\
Plagioclase & 4.08 & 9.23 & 15.12 \\
Magmatic debris & 2.99 & 6.7 & 4.11 \\
Metamorphic rock debris & 25.61 & 16.3 & 16.68 \\
Sedimentary rock debris & 24.46 & 20.64 & 3.66 \\
Mica & 0.19 & 1.63 & 0.98 \\
Flint & 1.48 & 0.66 & 0 \\
\hline
\end{tabular}

\section{Materials and methods}

\section{Materials}

Through thin section observation and analysis of 76 samples from 32 core Wells in The third member of Shahejie Formation in Chezhen sag, the detrital particle composition of each sub-member of the target formation in Chezhen sag was statistically analyzed (Table 1). On the whole, the contents of mica and chert in all subsections are very low. Due to provenance and sedimentation, there are some differences in the composition of clastic grains in each sub-member.

Due to the differences in the distance and hydrodynamic conditions between different sub-structural zones (steep slope zone, depression zone, gentle slope zone) and provenance, the detrital particle composition of the faulted basin is also affected. Therefore, the detrital particle compositions of different secondary structural belts of the third member of Shahejie formation in Chezhen Sag were analyzed in this paper (Table 2). From the steep slope to the depression zone and then to the gentle slope zone, the content of clastic quartz increases gradually, the content of feldspar increases slightly but does not change much, the content of debris decreases obviously, and the hybrid base and cement also decreases. The above characteristics indicate that along the provenance direction, the compositional maturity of parent rock also increases with the increasing distance of transportation.

To further analyze the physical property distribution characteristics of different secondary structural zones in

Table 2 Statistical table of detrital particles composition in each secondary tectonic zone of the third member of Shahejie Formation in Chezhen Depression

\begin{tabular}{lllllllrrrr}
\hline Secondary structure & Horizon & Quartz & Feldspar & $\begin{array}{l}\text { Potassium } \\
\text { feldspar }\end{array}$ & Plagioclase & Rock debris & Mica & Matrix & Cement \\
\hline Steep slope zone & $\mathrm{Es}_{3}$ & 25.3 & 22.8 & 12.1 & 10.7 & 51.8 & 0.1 & 11.7 & 11.6 \\
Sag zone & $\mathrm{Es}_{3}$ & 35.1 & 29.6 & 16.1 & 13.5 & 35.1 & 0.2 & 8.9 & 9.3 \\
Gentle slope zone & $\mathrm{Es}_{3}$ & 45.1 & 28.1 & 12.8 & 15.3 & 26.4 & 0.4 & 6.7 & 9.5 \\
\hline
\end{tabular}


the Chezhen Sag, we conducted a statistical analysis of the different levels of porosity and permeability of the reservoirs in each secondary structural zone (Table 3 ).

\section{Methods}

Sedimentary facies identification is mainly based on various facies markers which are obtained and determined from geology and logging. Geological methods determine rock types and analyze their origin by studying the lithology, structure and structure of sedimentary rocks and sediments (Abudeif et al. 2016). Through regional comparison and comprehensive application of color, lithology, structure and structure characteristics of sedimentary rocks and sediments, sedimentary facies are analyzed, palaeogeography and palaeoenvironment are restored, and facies models are established (Radwan et al. 2021a, b, c). Logging facies method is to extract the change characteristics of logging curve (including amplitude and form, etc.) from a group of logging responses that can reflect formation characteristics to describe the formation and use various pattern recognition methods to study the lithology and sedimentary environment of the formation (Radwan et al. 2021a, b, c).

In this study, 76 rock samples were collected from 32 cores at different depths, such as C66, C660 and CG25. Using these rock samples, a large number of micro characterization experiments have been carried out by means of optical or electronic microscope (Kassem et al. 2021), such as thin section analysis, scanning electron microscope, X-ray diffraction analysis experiment, etc. On this basis, the characteristics of core, sedimentary structure, sedimentary facies and microfacies, and distribution of sedimentary system of paleogene sublustrine fan in the north belt of Chezhen Depression are systematically studied. For porosity in this study, Adobe Photoshop CS6 and Magic Wand Tool were used to select the ratio of pixels of pores in the cast slice in the dial to calculate the ratio of pores, and three cast slice photographs were selected for each sample to calculate the average value.

Table 3 Statistical table of average reservoir physical properties of $\mathrm{ES}_{3}$ sub-structural zones in Chezhen Sag

\begin{tabular}{llll}
\hline Horizon & Secondary structure & $\begin{array}{l}\text { Average } \\
\text { porosity }(\%)\end{array}$ & $\begin{array}{l}\text { Average } \\
\text { permeability } \\
\left(\times 10^{-3} \mathrm{um}^{2}\right)\end{array}$ \\
\hline $\mathrm{ES}_{3}$ & Steep slope zone & 2.97 & 2.78 \\
& Sag zone & 10.99 & 10.65 \\
& Gentle slope zone & 12.12 & 11.46 \\
\hline
\end{tabular}

\section{Results}

\section{Core characteristics}

In this study, sublacustrine fans are divided into landslide sublacquer and channel sublacquer fans. The two types of sublacustrine fans have different core characteristics. The slumping sublacquer fan is formed by further slumping of the nearshore underwater fan. The transport distance is relatively short, and the sorting roundness is poor. The gravel is mostly angular and sub-angular with a thick-layered block structure; the mudstone interlayer is less developed, crumpled, and enveloping; mudstone tearing and other deformation structures are more developed (Fig. 2a, b).

The channel-type lake fan has a long transport distance, poor sortability, and good roundness. The gravel is mostly sub-circular and elliptical, and the fan has a small singlelayer thickness. An overlying erosion structure is visible. The 'ABABAB' (Sedimentary structure of atypical turbidite) structure reveals parallel bedding sandstones of varying thickness above each graded bedding. The underlying layer was partially deformed owing to differential compaction (Fig. 2c-f).

\section{Sedimentary structure}

Core observations revealed that an incomplete Bauma sequence is a very common feature in the sublacustrine fan deposits in the study area (Cui and Yang. 2011) that is primarily manifested as grain size progressive bedding (Fig. 3a) and superimposed erosion. Structures (Fig. 3b) include, block bedding (Fig. 3c), parallel bedding (Fig. 3d), warp bedding (Fig. 3e), horizontal bedding (Fig. 3f), and lenticular bedding (Figure 3g). The deformed structures in the sublacustrine fan sediments in the study area include heavy-loaded structures (Fig. 3h), flame-like structures (Fig. 3i), ball pillow structures, landslide deformation structures, mudstone tearing debris, standing gravels, and boulders.

\section{Single-well facies analysis}

The sedimentary facies map of the Chezhen Sag (especially the single-well facies analysis) uses the following scale symbols: M-mud, diameter $<0.01 \mathrm{~mm}$; Si-silt sand, diameter $0.01-0.1 \mathrm{~mm}$; Sf-fine sand, diameter 0.1-0.25 mm; Sm-medium sand, diameter $0.25-0.5 \mathrm{~mm}$; Sc-coarse sand, diameter $0.5-1 \mathrm{~mm}$; Gf-fine gravel, diameter 1-10 mm; Gm-medium gravel, diameter 10-100 mm; 
Fig. 2 Core characteristics

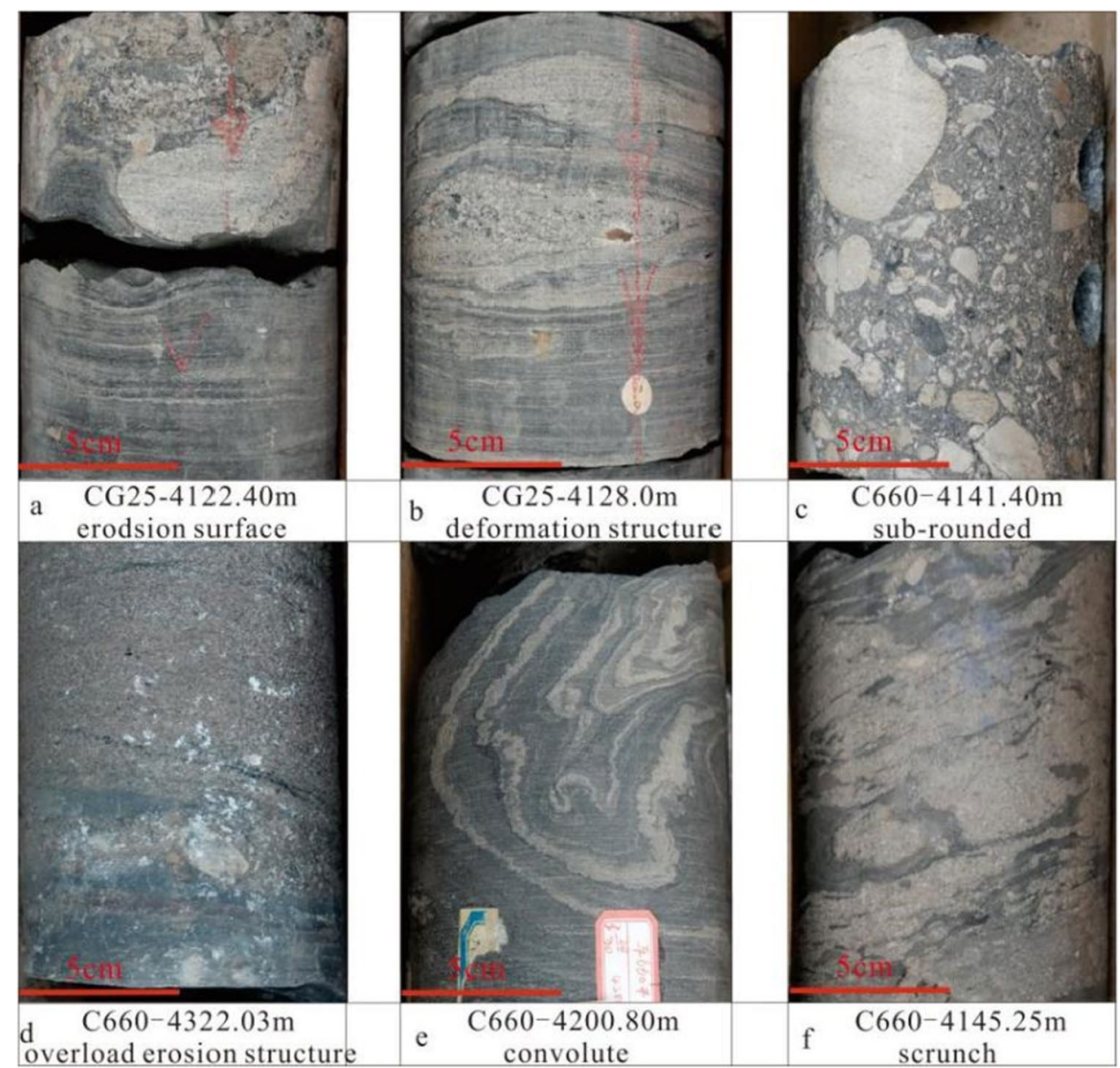

Gc-coarse gravel, diameter is $100-1000 \mathrm{~mm}$; coarse gravel is defined as the outer boundary and is limited to the core diameter; the grain size cannot exceed that of the coarse gravel (Fig. 4).

$\mathrm{ES}_{3}$ is the core section of Well C660. The lithology of the well section from 4138.4-4146.2 m includes gray conglomerate, dark gray mudstone, and interbedded sandstone; the mudstone contains oil spots at $4.6 \mathrm{~m}$. The gravel in the conglomerate is mostly carbonated, with better rounding, poor sorting, and overall coarser grain size. Mudstone is dark gray and mostly interbedded with sand and mudstone. The sedimentary environment is deep water.

The lithology of the well section from 4187 to $4204 \mathrm{~m}$ includes mudstone, sandstone, and conglomerate. The oil spot level in the sandstone is $3 \mathrm{~m}$, and the fluorescence level in the conglomerate is $5 \mathrm{~m}$ (two layers). The top of the coring is dominated by dark gray mudstone, and the bottom is conglomerate. The gravel in the conglomerate is mostly well-rounded and poorly sorted carbonate. The middle lithology includes medium sandstone and coarse sandstone; the lower lithology includes interbedded sand and mudstone then increasing mudstone with lenticular, horizontal bedding, and deformed structures.
The lithology of the well section from 4238.5 to $4244.7 \mathrm{~m}$ primarily includes conglomerate and sandstone; the conglomerate shows $6.8 \mathrm{~m}$ of oil spots. The gravel in the conglomerate is mostly well-rounded and poorly sorted carbonate; the sandstone changes downward from fine to medium, and the grain size becomes coarser.

The lithology of the well section from 4299.5 to $4305.5 \mathrm{~m}$ is primarily conglomerate, sandstone, and mudstone, without oil and gas. The gravel in the conglomerate is mostly well-rounded and poorly sorted carbonate, and the sandstone is coarse. The mudstone is dark gray with intercalated sandstone and a deformed structure.

\section{Sedimentary facies and microfacies characteristics}

The submarine fan can be divided into the inner fan (upper fan and fan root), middle fan, and outer fan (outer fan and fan edge) (Zhao and Liu. 1984). The two types of sublacustrine fans studied in this paper (slump or channel sublacquer fans) can be divided into three subfacies: inner, middle, and outer fans. The middle fan is the most developed, followed by the outer fan, and the inner fan. The main channel microfacies developed in the inner fan

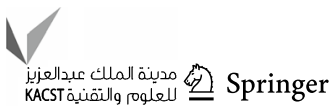


Fig. 3 Sedimentary structure
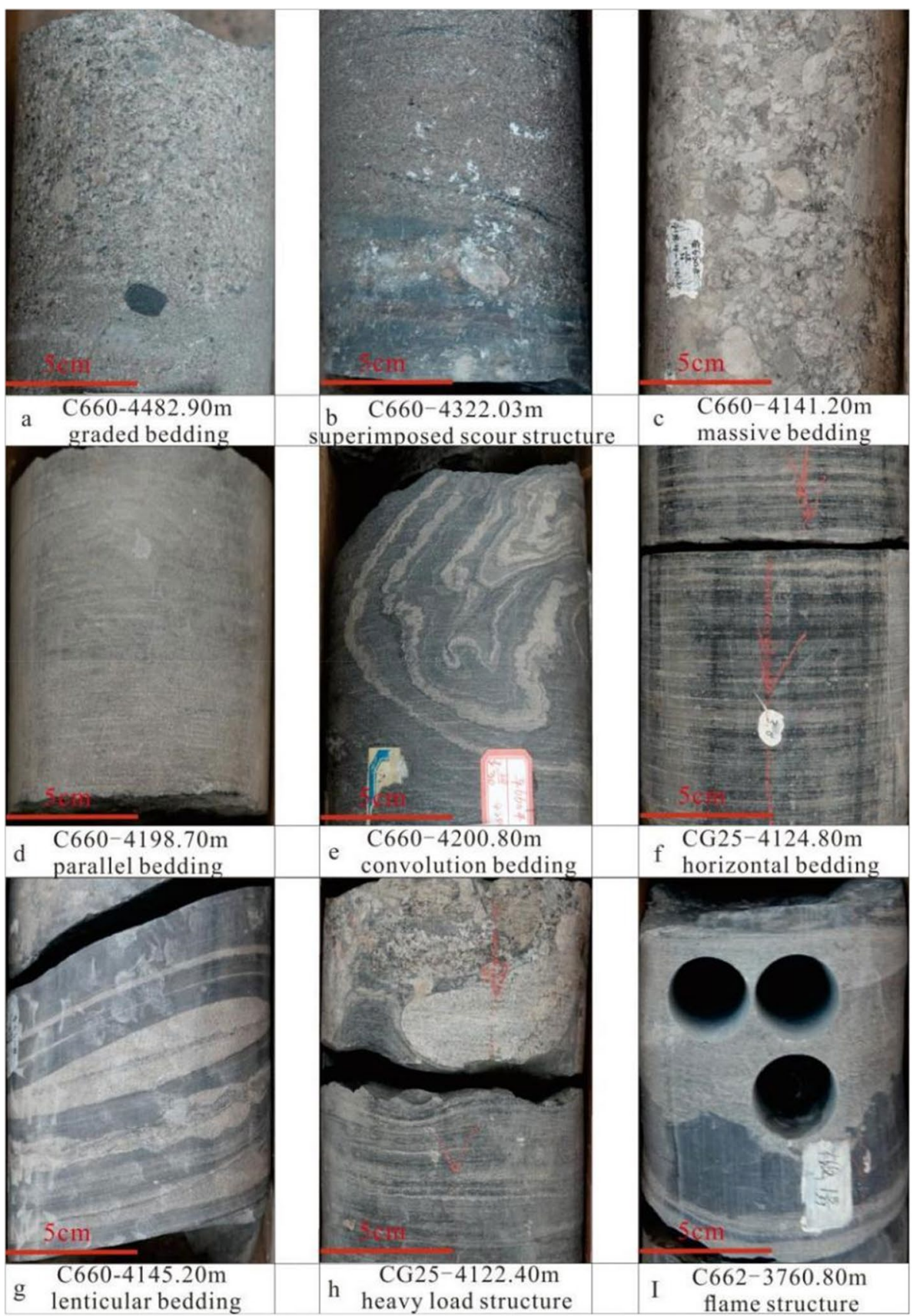

and feature coarse lithology dominated by conglomerate and supported by a heterogeneous base with a mostly thick-layered block structure with few mudstone interlayers. Braided channel microfacies developed in the middle fan, and gravel-bearing and conglomerate mediumcoarse sandstones are dominant. The mudstone interlayers increased significantly, and the outer fan developed peripheral microfacies dominated by mudstone intercalated with thin-bedded sandstone and siltstone.

\section{Main channel microphase}

The microfacies of the main channel show multiple superposed positive granular sequences produced by the sedimentation of terrigenous detrital material on the northern steeply sloped zone during the lowstand zone period of a sequence transported by floods to the semi-deep lake area. The braided channel and turbidite leaf body developed at the front end remain the core sedimentary units; however, 


\begin{tabular}{|c|c|c|c|c|c|c|c|c|c|c|c|c|}
\hline \multicolumn{5}{|c|}{ Formation } & $\mathrm{AC}$ & \multirow[b]{2}{*}{$\begin{array}{c}\text { Depth } \\
\text { (m) }\end{array}$} & \multirow[b]{2}{*}{ Core histogram } & \multirow[b]{2}{*}{$\begin{array}{c}\text { Lithologic description } \\
\text { section } \\
\text { MSiSfSmScGfGmGc }\end{array}$} & \multirow[b]{2}{*}{$\begin{array}{c}\text { Lithologic } \\
\text { characteristics }\end{array}$} & \multirow[b]{2}{*}{ 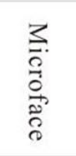 } & \multirow[b]{2}{*}{ 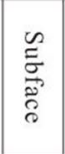 } & \multirow[b]{2}{*}{$\begin{array}{l}T \\
\overrightarrow{0}\end{array}$} \\
\hline$\frac{2}{0}$ & 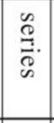 & $\begin{array}{l}n \\
c \\
0 \\
0 \\
\Xi\end{array}$ & 足 & 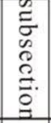 & $\begin{array}{lll}50 & \text { GR } & 150 \\
& \text { API } & 150\end{array}$ & & & & & & & \\
\hline \multirow{5}{*}{ 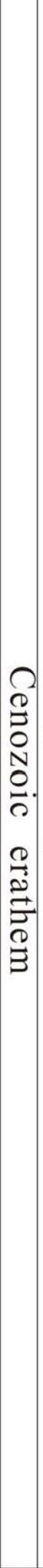 } & \multirow{5}{*}{$\mid \begin{array}{c}1 \\
0 \\
0 \\
0 \\
0 \\
0 \\
0 \\
0 \\
0 \\
0 \\
0 \\
0 \\
3\end{array}$} & \multirow{4}{*}{ 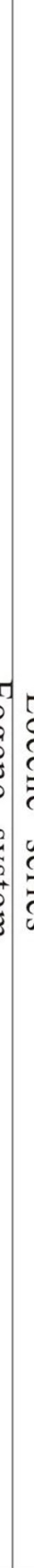 } & \multirow{5}{*}{$\begin{array}{l}0 \\
0 \\
0 \\
0 \\
0 \\
0 \\
0 \\
0 \\
0 \\
0 \\
0 \\
0 \\
0 \\
0 \\
0\end{array}$} & & & $\begin{array}{r}4138- \\
4140- \\
4142- \\
4144- \\
4146-\end{array}$ & 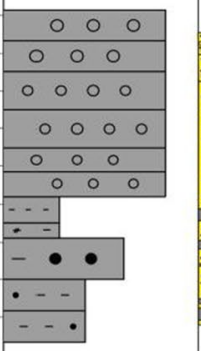 & 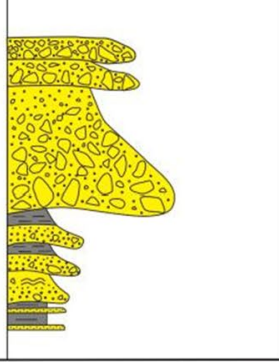 & $\begin{array}{c}\text { Fine } \\
\text { conglomerate } \\
\text { Medium } \\
\text { sandstone } \\
\text { Medium } \\
\text { conglomerate } \\
\text { Mudstone } \\
\text { Argillaceous } \\
\text { sandstone } \\
\text { Sandy } \\
\text { mudstone }\end{array}$ & 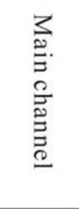 & 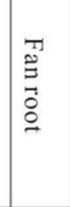 & 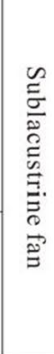 \\
\hline & & & & & & $\begin{array}{l}4186 \\
4188- \\
4190- \\
4192- \\
4194- \\
4196-\end{array}$ & 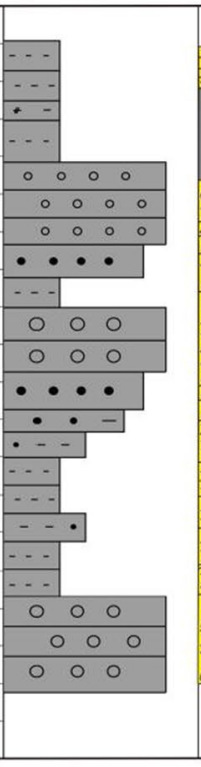 & - & $\begin{array}{l}\text { Medium } \\
\text { sandstone } \\
\text { Mudstone } \\
\text { Fine } \\
\text { conglomerate } \\
\text { Medium } \\
\text { sandstone } \\
\text { Coarse } \\
\text { sandstone } \\
\text { Medium } \\
\text { conglomerate } \\
\text { Medium } \\
\text { sandstone } \\
\text { Argillaceous } \\
\text { sandstone } \\
\text { Siltstone } \\
\text { Medium } \\
\text { conglomerate }\end{array}$ & 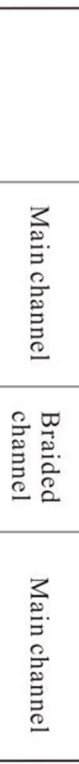 & 荬 $\frac{3}{\frac{3}{2}}$ & 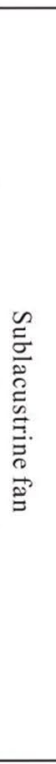 \\
\hline & & & & & & $\begin{array}{r}4238- \\
4240- \\
4242- \\
4244- \\
4246\end{array}$ & 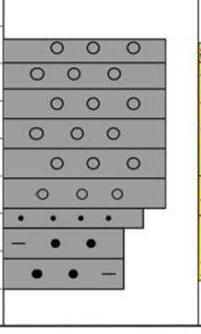 & 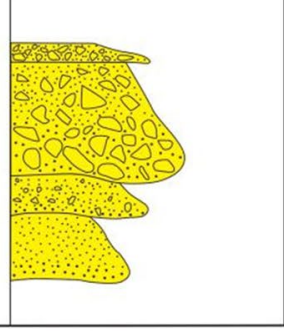 & $\begin{array}{c}\text { Fine } \\
\text { conglomerate } \\
\text { Medium } \\
\text { conglomerate } \\
\text { Fine } \\
\text { conglomerate } \\
\text { Coarse } \\
\text { sandstone }\end{array}$ & 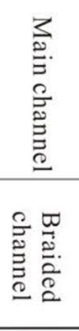 & $\begin{array}{l}3 \\
\frac{3}{2} \\
\frac{2}{0} \\
\frac{\vec{\partial}}{\Xi}\end{array}$ & 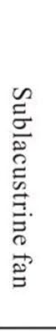 \\
\hline & & & & & & $\begin{array}{l}4298 \\
4300-\end{array}$ & \begin{tabular}{cccc}
$\circ$ & 0 & 0 \\
\hdashline & 0
\end{tabular} & 0 & $\begin{array}{c}\text { Fine } \\
\text { conglomerate }\end{array}$ & 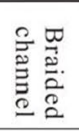 & 离 $\frac{3}{0}$ & 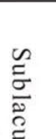 \\
\hline & & & & & & $\begin{array}{r}4302- \\
4304- \\
4306\end{array}$ & 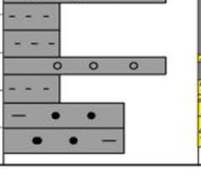 & A- & $\begin{array}{l}\text { Mudstone } \\
\text { Medium } \\
\text { sandstone } \\
\text { Fine } \\
\text { sandstone } \\
\end{array}$ & 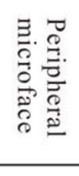 & 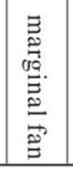 & 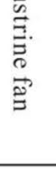 \\
\hline
\end{tabular}

Fig. $4 \mathrm{ES}_{3}$ single-well facies of the Shahejie Formation (Well C660) 


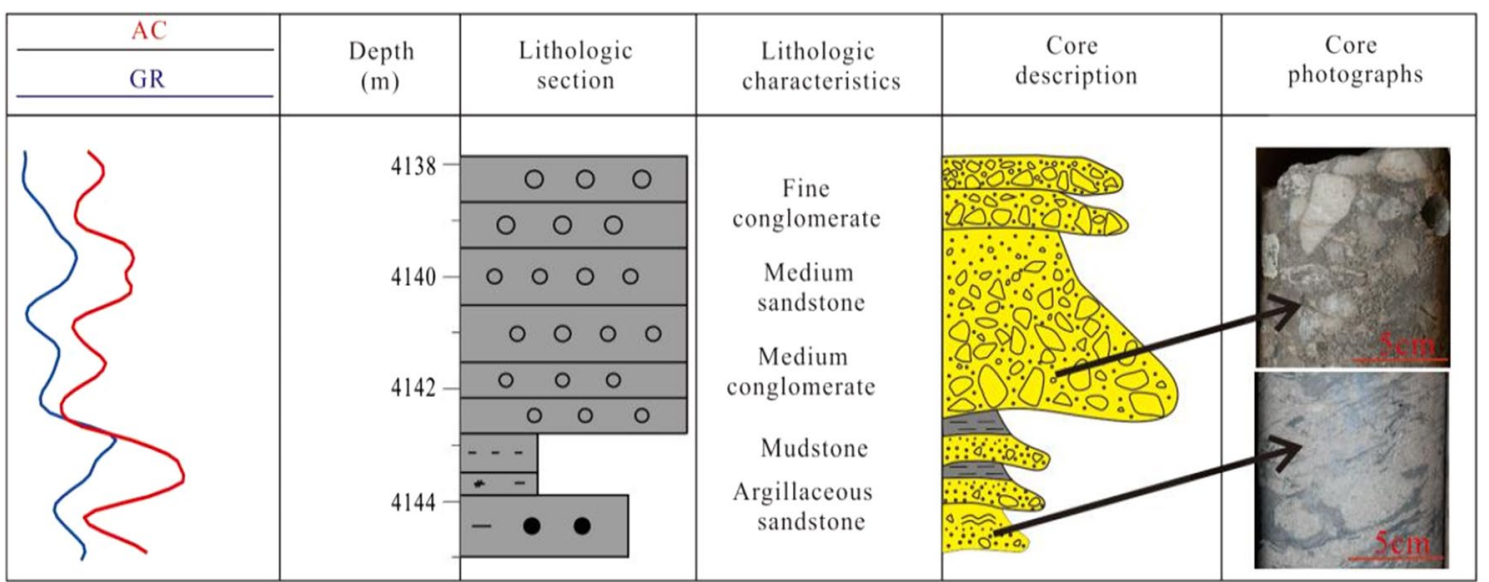

Fig. 5 Microfacies characteristics of the main channel (Well C660)

the single-stage glutenite bodies are thin, underwater gravity flow is frequently diverted, and multi-stage sublacustrine fan deposits are superimposed. The lithology is primarily sub-angular-sub-circular, poorly sorted medium gray-black conglomerate and gravel-bearing sandstone with a high content of miscellaneous bases. Sedimentary structures include positive-grained progressive bedding, deformed structures, and erosion surfaces. The natural potential is a superposition of the box, funnel, and bell shapes (Fig. 5).

\section{Braided channel microfacies}

Braided channel microfacies primarily developed in the middle fan subfacies in the study area. The lithology is primarily gray conglomerate sandstone and conglomerate. The gravel is well-rounded with poor sortability. Deposition structures include parallel bedding and scouring surfaces. The medium-and high-amplitude toothed spontaneous potential curve is box-shaped, bell-shaped, and finger-shaped (Fig. 6).

\section{Peripheral microfacies}

The lithology of the outer fan primarily consists of thin interbedded dark gray sand and mudstone with parallel bedding and deformed structures. The natural potential curve becomes a low-amplitude tooth shape (Fig. 7).

\section{Discussions}

\section{Sedimentary system distribution characteristics}

Statistics reveal that the sublacustrine fans developed at the largest scale in the early depositional stage of $\mathrm{ES}_{3}{ }^{3}$ (Zhou

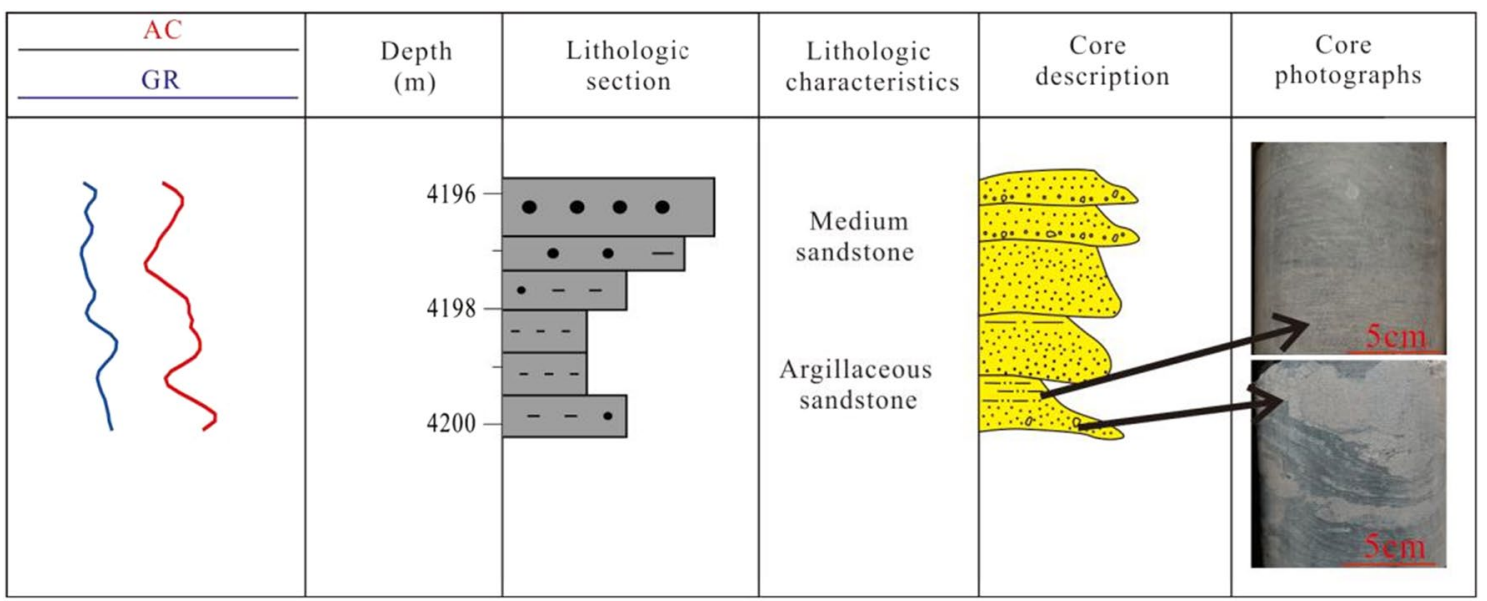

Fig. 6 Microfacies characteristics of the braided channels (Well C660) 


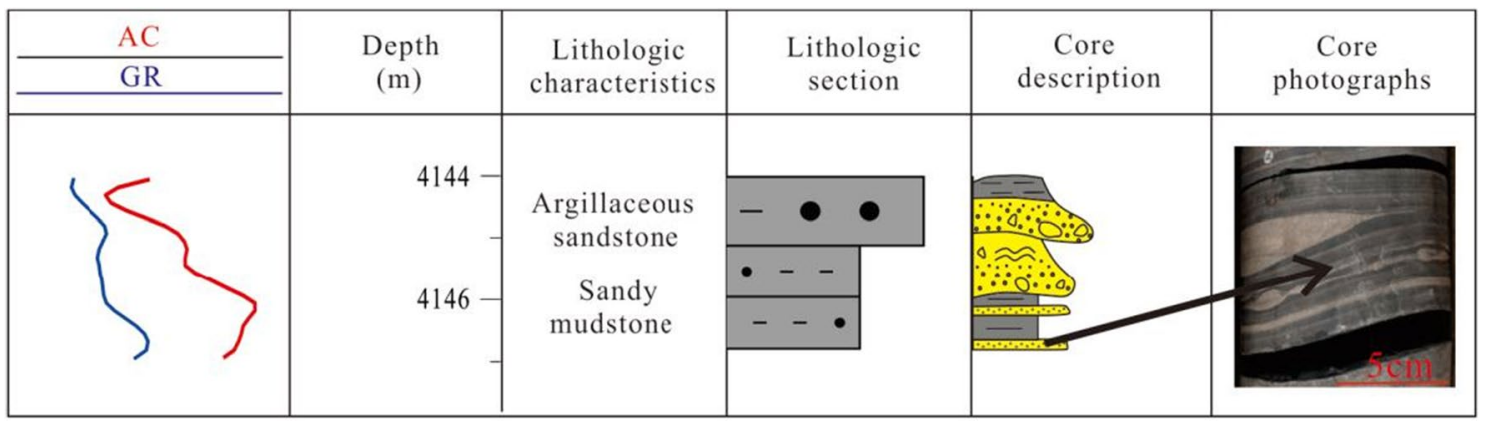

Fig. 7 Peripheral microfacies characteristics (Well C660)

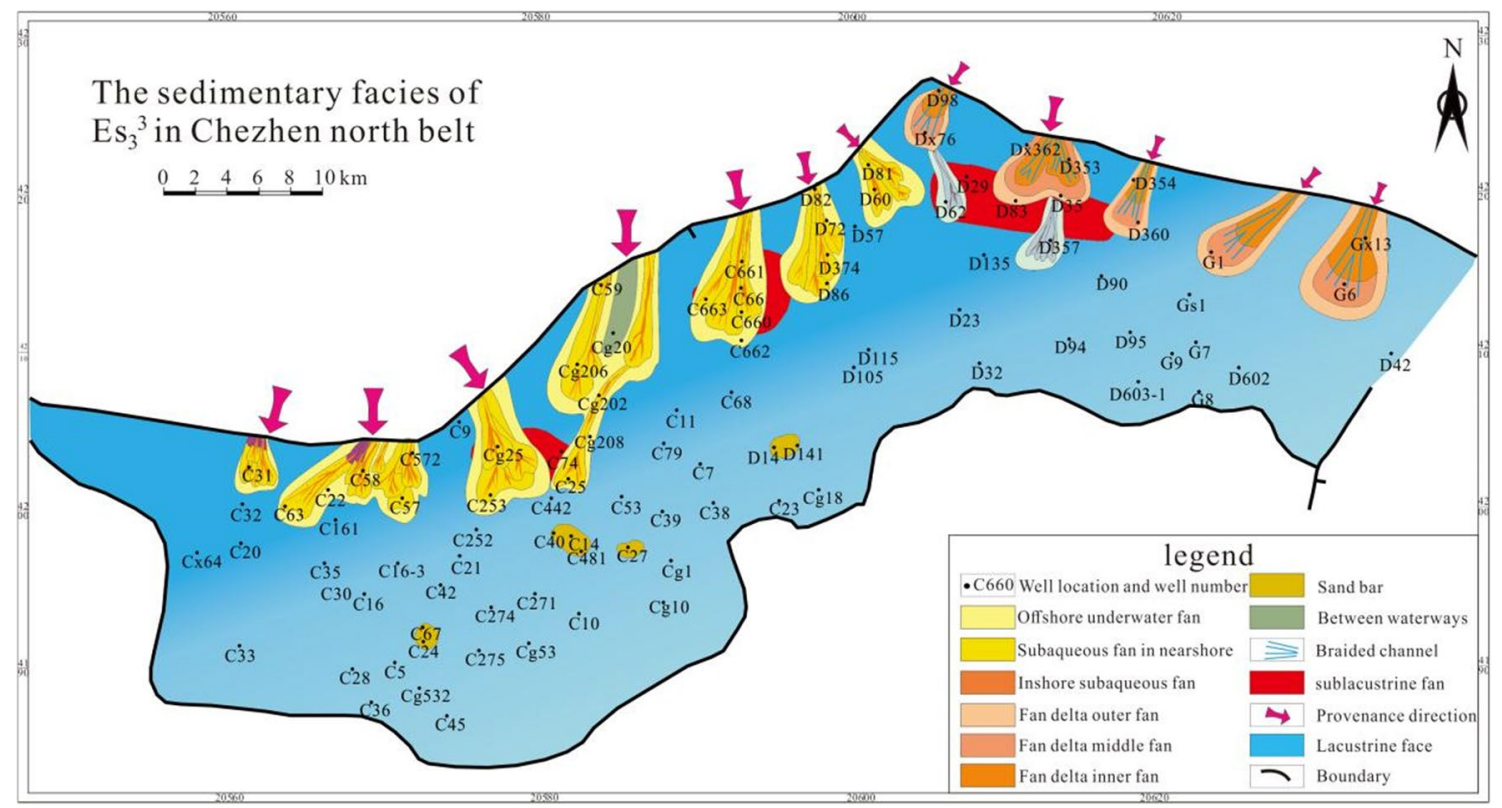

Fig. 8 Sedimentary facies of $\mathrm{Es}_{3}{ }^{3}$ in the Chezhen north zone

et al. 2007). C66, C660, and CG25 developed to varying degrees on the same plane; $\mathrm{ES}_{3}{ }^{2}$ and $\mathrm{ES}_{3}{ }^{1}$ developed in the deep depression in the early depositional stage through small-scale sublacustrine fan deposition (Fig. 8).

The activity and occurrence of the boundary faults in the rifted lake basin and their combined relationship with secondary faults determine the geomorphic pattern and characteristics of the steeply sloped and depression zones. The research results of the fracture structure of the steeply sloped zone in the Chezhen Sag reveal that the boundary fracture structure of the steeply sloped zone is divided into shoveldown concave (A), fault step (B), slope (C), and shovel-up convex (D) types. The sublacustrine fan deposits developed in the shovel-under concave (A) and fault step (B) fault structures (Fig. 9).

Fault structures have different section morphologies, occurrences, fault activity intensities, and development area characteristics; the types of sedimentary facies in different fault structures also differ. Sublacustrine fan deposits are underdeveloped in the shovel-up convex (D) fault structure and are difficult to develop in the slope type (C) fault structure (Fig. 10).

\section{Sedimentary model}

We established a sublacustrine fan deposition model of the study area based on the structural evolution characteristics and sedimentary facies research results of the Bohai Bay Basin (Fig. 11). The sedimentary model describes the relationship among the sedimentary environment, sedimentation, and the sedimentary facies and provides a theoretical summary of the cause of the sedimentary facies. The sedimentary model reflects the most typical characteristics of sedimentary facies, the formation mechanism and process 
Fig. 9 Boundary fault structure-sedimentary model: AShovel-down concave, BFault step type

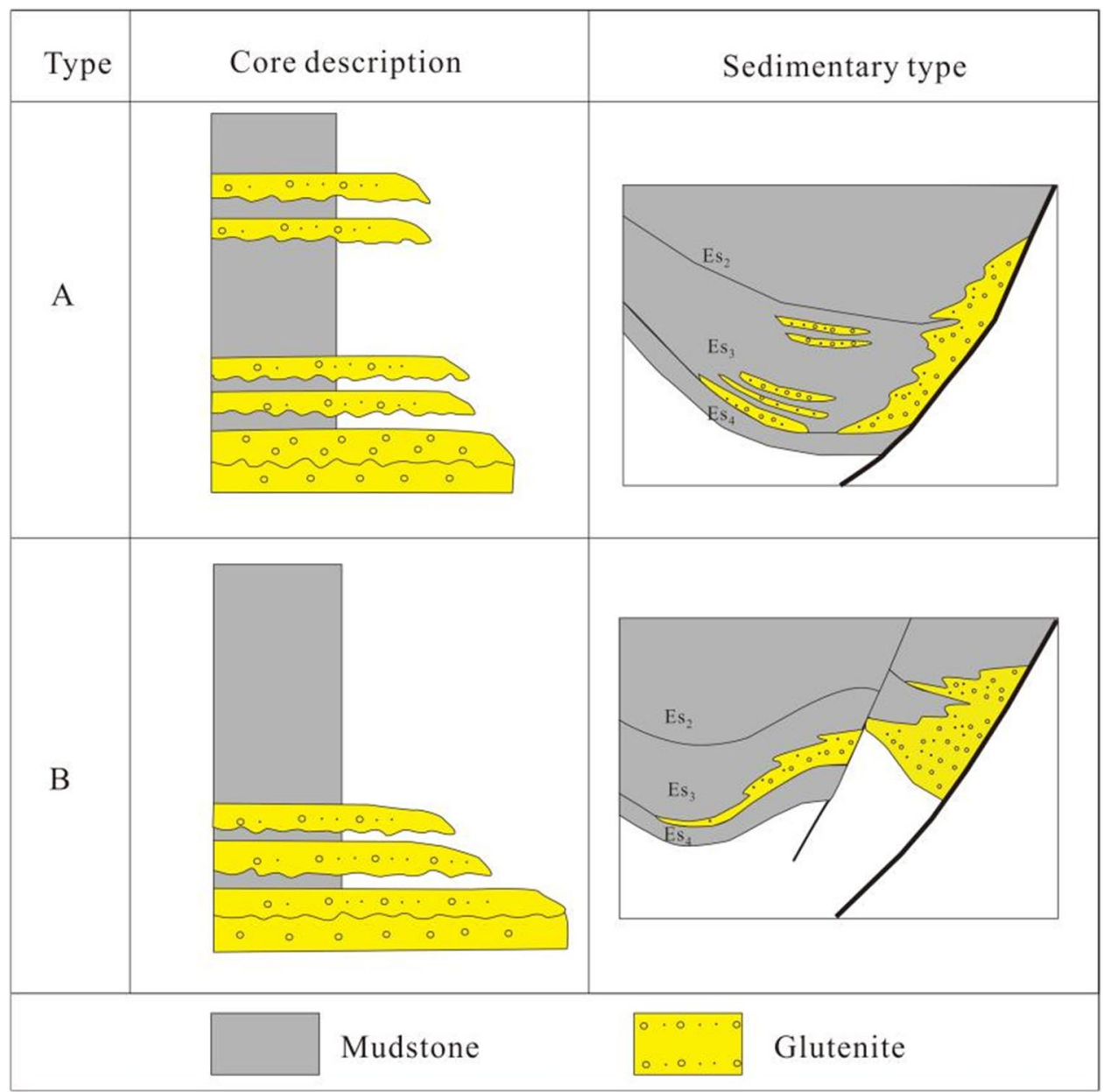

of sedimentary facies, and the basic relationship between sedimentary facies and the environment. The development of sublacustrine fans primarily occurs in low-stand regions and in the lower part of lacustrine transgressive regions during the base-level ascending period. The fans are primarily distributed from the center of the depression to the gentle slope, and the facies zones are widely spread across 5-10 km. The sublacustrine fan has a long transport distance and a wide spread of facies zones and is a fan formed by mountain floods that directly enter the lake basin. The source of the fan are the turbidity deposits in the Chengzikou bulge. The parent rock composition is primarily Lower Paleozoic aphanitic limestones. The deposition center of the lake basin is south of the onset of the $\mathrm{Es}_{3}{ }^{3}$ deposition, and a set of fans was deposited in low-lying areas. Later, the activity of the Chengnan Fault and the expansion of the lake basin moved the deposition center northward and created a new deposition center and fan body. Thus, tectonic movement gradually formed numerous fans with degraded characteristics.

The formation and evolution of the sublacustrine fan could be caused by further slumping of the nearshore underwater fan across a relatively short transportation distance or by gravity flow from floods directly entering the deep water area of the lake across a relatively long transportation distance.

\section{Analysis of the influence degree of sedimentation on reservoir properties}

(1) The analysis of rock test data revealed that the glutenite body deposited by the sublacustrine fan often has a large burial depth (greater than 3500 or $40,000 \mathrm{~m}$ ), coarse grain size (primarily medium and fine conglomerate), and poor separation (supported by miscellaneous foundations). Consequently, the reservoirs have low porosity, low permeability, ultra-low porosity, and ultra-low permeability. The sublacustrine fan glutenite body formed in the deep depression period is interspersed with semi-deep lake source rock, and the source-reservoir-caprock combination is superior.

The overall physical properties of the $\mathrm{ES}_{3}$ reservoir in the steeply sloped zone of the Chezhen Sag are poor, with an average porosity of less than $3 \%$. The physical properties of the reservoirs in the sag zone and the gently sloped zone of the Chezhen Sag are not significantly different. The reservoir 
Fig. 10 Boundary fault structure-sedimentary model: CSlope type, DShovel-up convex

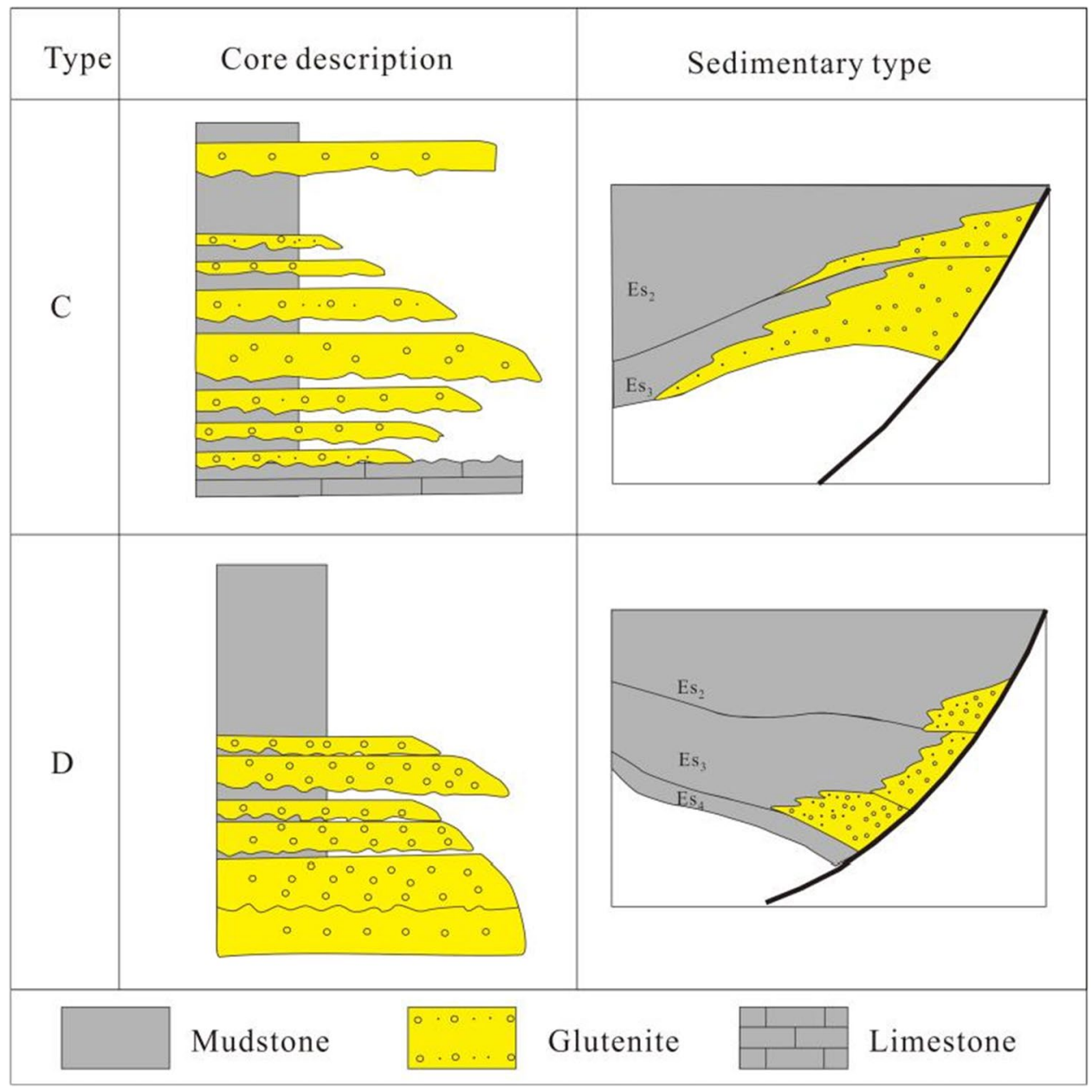

Fig. 11 Sedimentary model of the sublacustrine fan (Channel, Subaqueous fan or delta, Slump sublacustrine fan, Shoal patch, Channel sublacustrine, Lacustrine deposits)

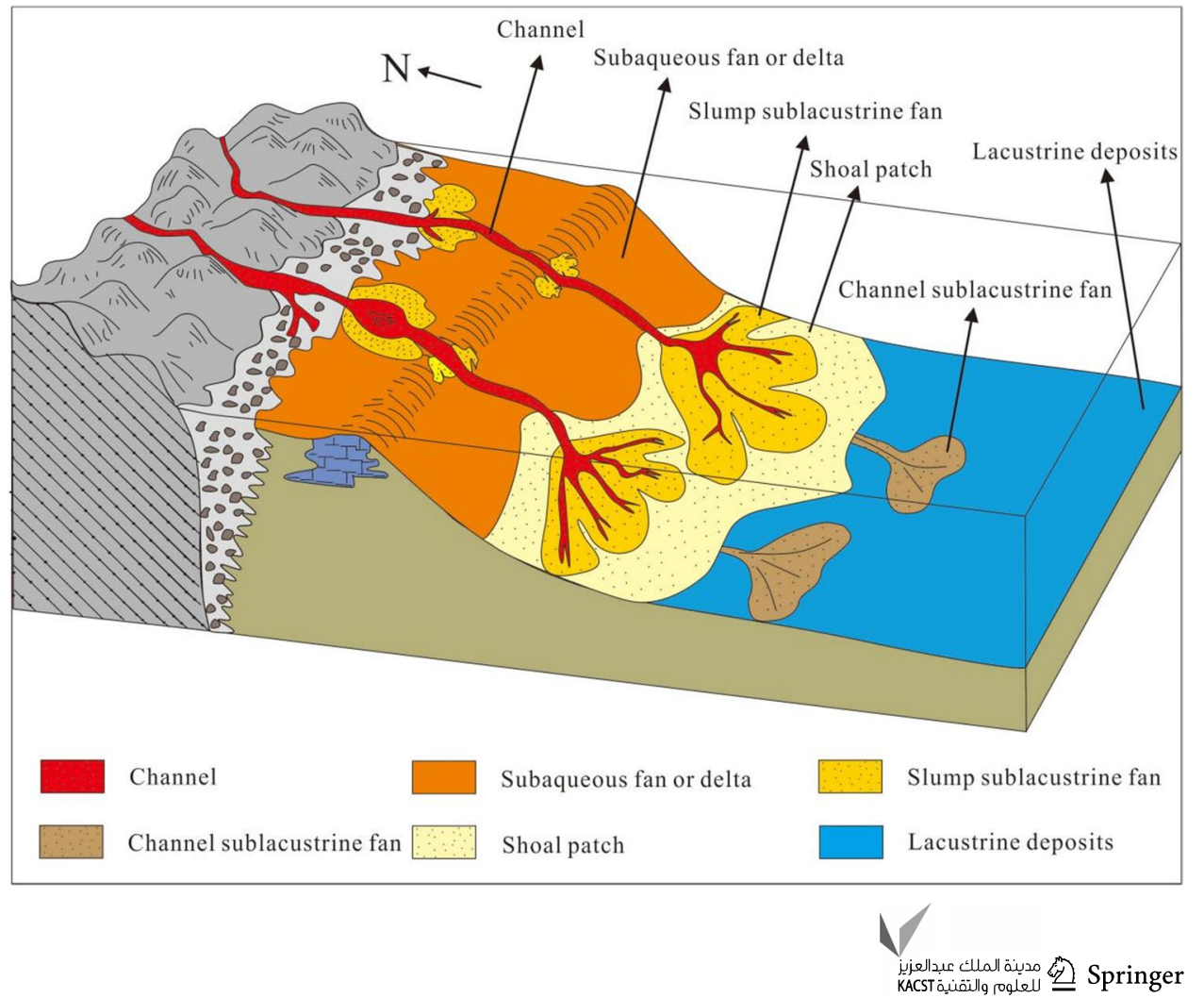


physical properties of the gently sloped zone are slightly higher than those of the sag zone and much higher than those of the steeply sloped zone. To further analyze the physical property distribution characteristics of different secondary structural zones in the Chezhen Sag (Radwan et al. 2021a, b, c), we conducted a statistical analysis of the different levels of porosity and permeability of the reservoirs in each secondary structural zone (Wang et al. 2014).

The similar physical properties of the depression zone and the gently sloped zone in the Chezhen Sag allowed a combined statistical analysis. The results show that $81 \%$ of $\mathrm{ES}_{3}$ in the steeply sloped zone of the Chezhen Sag has a reservoir porosity of less than $5 \% ; 70 \%$ of the reservoir has a permeability less than $1 \times 10^{-3} \mathrm{um}^{2}$ (Fig. 12a, b). The porosity of $63 \%$ the $\mathrm{ES}_{3}$ reservoirs in the gently sloped zone and the Chezhen Sag is distributed between 10 and $20 \%$, and the percentage of permeability higher than $1 \times 10^{-3} \mathrm{um}^{2}$ reaches $53 \%$ (Fig. 12c, d).

(2) The $\mathrm{ES}_{3}{ }^{3}$ sublacustrine fan glutenite reservoir in the Chezhen Sag primarily developed two storage spaces: secondary pores and fractures. According to the contact relationship between pores and grains and the distribution position of pores in the rock, secondary pores can be divided into grains, interpores, and intragranular pores. Fractures include diagenetic fractures, glued-grain fractures, and microcracks. The sublacustrine fan reservoir is affected by compaction, and diagenetic fractures are widely developed (Fig. 13a) and largely formed by the compaction and fracture of rigid particles (quartz and feldspar) (Fig. 13b). The cracks developed between clastic particles (Fig. 13c) can be used as migration channels for reservoir fluids to improve reservoir permeability. The development site of the microfractures contains the local dissolution zone (Fig. 13d). Microfractures acting as fluid migration channels improve the reservoir physical properties (Radwan et al. $2021 \mathrm{a}, \mathrm{b}, \mathrm{c}$ ). Irregular microcracks are visible under an electron microscope (Fig. 13e). The early formed microcracks can be filled with clay minerals (Fig. 13f), which affects the drainage performance of the cracks.

\section{Conclusion}

(1) Glutenite bodies are widely developed in the northern zone of the Chezhen Sag, and the sublacustrine fan is an important genetic type. The Paleogene sublacustrine

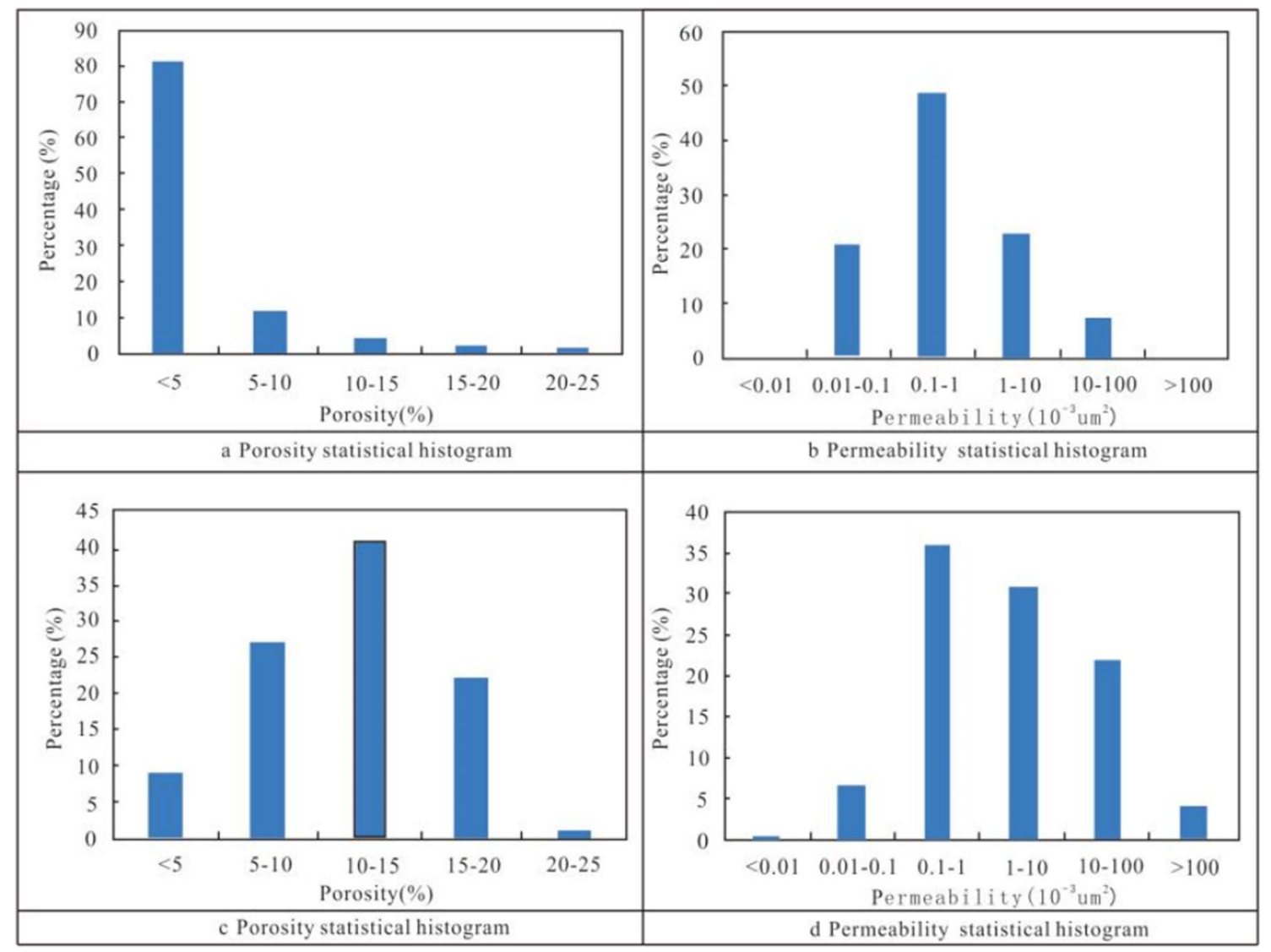

Fig. 12 Statistical histogram of porosity and permeability 


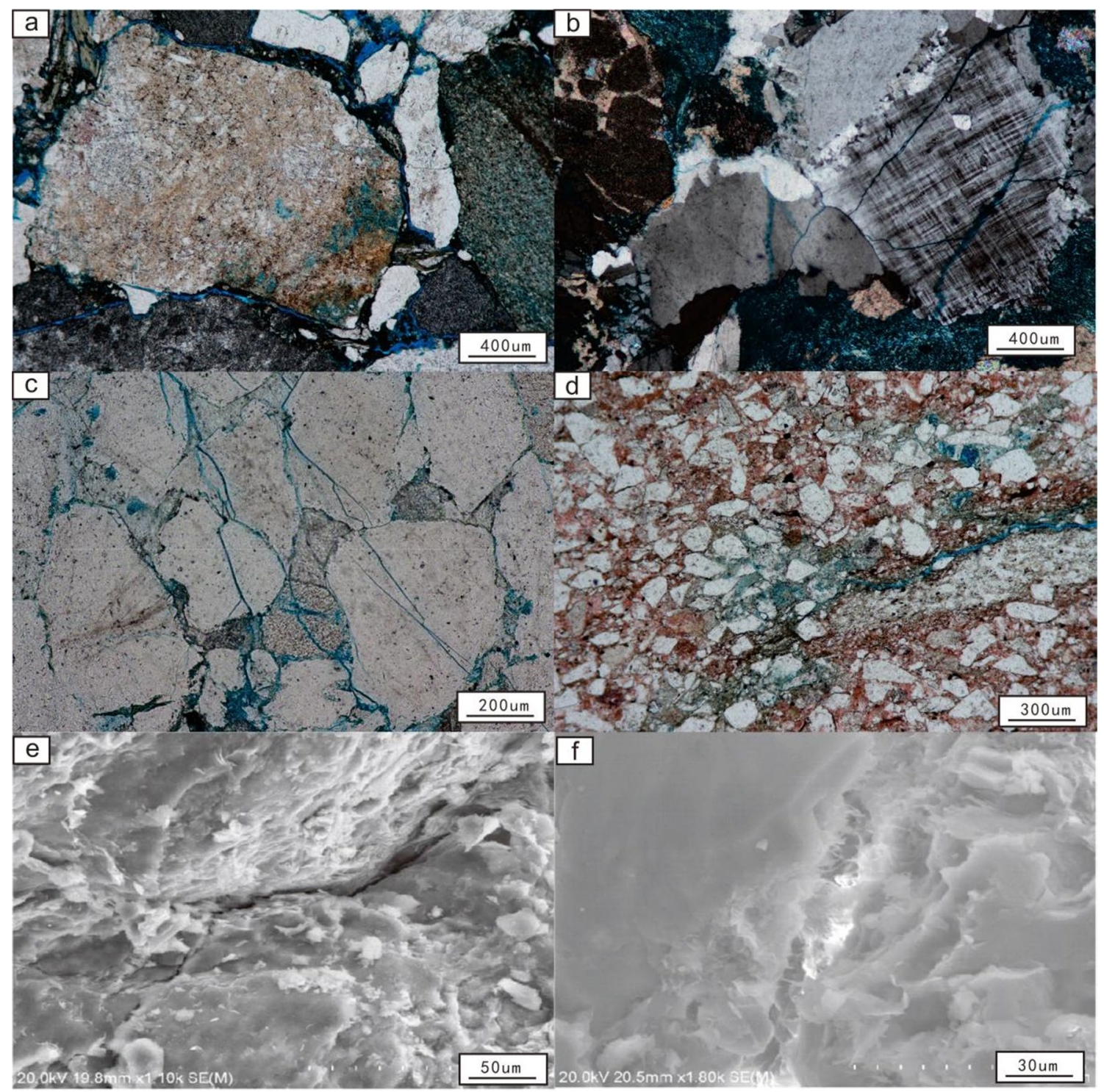

Fig. 13 Fracture development characteristics of $\mathrm{ES}_{3}$ in the Chezhen Sag: aC406, $3035.10 \mathrm{~m}$, well-developed diagenetic fractures, monopolarization; b CG20, $2551.20 \mathrm{~m}$, fracture broken by compaction of feldspar particles, orthogonal light; c D72, $3098.71 \mathrm{~m}$, glu- ing seam, monopolarization; d C272, $2603.10 \mathrm{~m}$, microfractures; e C57, $4217.78 \mathrm{~m}$, microfracture; f CG25, $5051.61 \mathrm{~m}$, filamentous illite developed in the microfractures fans in the Bohai Bay Basin are primarily distributed in $\mathrm{ES}_{3}$.

(2) The transportation distance of the slump-type sublacustrine fan in the northern zone of the Chezhen Sag was relatively short, and the gravels are mostly angular and sub-angular, thick-layered, and massive; the mudstone interlayers are relatively undeveloped. The channeltype sublacustrine fan sand-conglomerate body (one of the most important exploration targets of the northern zone) was transported over long distances; the gravel is mostly sub-circular or elliptical, with well-developed argillaceous interlayers, good physical properties, and a superior source-reservoir-caprock combination.

(3) The glutenite deposited in the sublacustrine fan is characterized by large burial depth, coarse grain size, and poor sorting roundness, which lead to low porosity, low permeability, and ultra-low porosity and ultra-low permeability reservoirs. The glutenite is characterized by secondary pores and microfractures, which play an important role in improving the physical properties of the glutenite reservoir. 
Acknowledgements The authors would like to thank the workers of Shengli Oilfield of Sinopec for supplying research data.

Funding This work was supported by the Natural Science Foundation of Shandong Province (ZR2020MD035) and the National Natural Science Foundation of China (51674156).

\section{Declarations}

Conflict of interest The authors declare that they have no known competing financial interests or personal relationships that could have appeared to influence the work reported in this paper.

Open Access This article is licensed under a Creative Commons Attribution 4.0 International License, which permits use, sharing, adaptation, distribution and reproduction in any medium or format, as long as you give appropriate credit to the original author(s) and the source, provide a link to the Creative Commons licence, and indicate if changes were made. The images or other third party material in this article are included in the article's Creative Commons licence, unless indicated otherwise in a credit line to the material. If material is not included in the article's Creative Commons licence and your intended use is not permitted by statutory regulation or exceeds the permitted use, you will need to obtain permission directly from the copyright holder. To view a copy of this licence, visit http://creativecommons.org/licenses/by/4.0/.

\section{References}

Abudeif AM, Attia MM, Radwan AE (2016) Petrophysical and petrographic evaluation of Sidri Member of Belayim Formation, Badri field, Gulf of Suez, Egypt. J African Earth Sci 115:108-120

Cui W, Yang Y (2011) Using log data to identify gravity flow deposits and its significance. Lithologic Reservoirs. 23(5)

Cumberpatch Z, Kane I, Soutter E, Hodgson D, Jackson C, Kilhams B, Poprawski Y (2021) Interactions between deep-water gravity flows and active salt tectonics. J Sediment Res 91(1):34-65

Fan Z (2007) The origin of sublacustrine fan and its significance for exploration in Northern Chexi Sub-Sag. Jiyang Depression Xinjiang Pet Geol 28(1):48-50

Haghjouei H, Rahimpour M, Qaderi K, Kantoush S (2021) Experimental study on the effect of bottomless structure in front of a bottom outlet on a sediment flushing cone. Int J Sedim Res 36(3):335-347

Kassem AA, Hussein WS, Radwan AE, Anani N, Abioui M, Jain S, Shehata AA (2021) Petrographic and diagenetic study of Siliciclastic Jurassic sediments from the Northeastern Margin of Africa: implication for reservoir quality. J Pet Sci Eng 200:108340

Li L, Lin H, Fan Z, Bi C, Shi Q (2008) Reservoir characteristics and influencing factors of Paleogene glutenite in the northern Chezhen zone. Oil Gas Technol 30(2):410-413

Liu M, Zhao C (1984) Sedimentary characteristics of Paleogene sublacustrine fan in Bohai Bay Basin. East China Pet Inst 8(3):223-235

Liu X, Wan X, Lin J, Li H, Mu J (2003) Continental Turbidite deposition system and hydrocarbon. Acta Geosci Sin 24(1):61-66

Liu J, Zhang P, Li Q, Lan B, Wang N (2009) Seismic description technology of glutenite reservoir in North Chezhen. Oil Gas Technol 31(1):205-206

Liu G, Fu J, Yang H, Xu L (2013) Application of Structural Characteristics Research in Chezhen Sag, Jiyang depression, Bohai Bay basin in oil and gas exploration. China Sci Technol Rev

Lu Z (2008) Influence of the Paleogene structural styles on deposition and reservoir in Chezhen Sag, Bohai Bay Basin. Palaeogeography 10(3):277-285

Nguidi M, Mouflih M, Benbouziane A, Kocsis L, El Ouariti S, El 1 Boukhari H, Aquit M, Yazami OK (2021) Lithofacies analysis, sedimentary dynamics and genesis of Maastrichtian-Eocene phosphorites of BouCraa deposit (southern Morocco). J African Earth Sci 177(1): 104161

Peng Y, Huang H, Luo Q (2007) Fine analysis of sedimentary facies in the lower third member of Shahejie formation from block Che 66 in Chezhen Sag. Jiyang Depression Geosci 21(4):705-711

Radwan AE (2021) Modeling the depositional environment of the sandstone reservoir in the middle miocene sidri member, badri field, gulf of suez basin, Egypt: integration of gamma-ray log patterns and petrographic characteristics of lithology. Nat Resour Res 30:431-449

Radwan AE, Rohais S, Chiarella D (2021) Combined stratigraphicstructural play characterization in hydrocarbon exploration: a case study of Middle Miocene sandstones, Gulf of Suez basin, Egypt. J Asian Earth Sci 218:104686

Radwan AE, Trippetta F, Kassem AA, Kania M (2021) Multi-scale characterization of unconventional tight carbonate reservoir: Insights from October oil filed, Gulf of Suez rift basin, Egypt. J Pet Sci Eng 197:107968

Radwan AE, Nabawy BS, Kassem AA, Hussein WS (2021) Implementation of rock typing on waterflooding process during secondary recovery in oil reservoirs: a case study, El Morgan Oil Field, Gulf of Suez, Egypt. Nat Resour Res. https://doi.org/10. 1007/s11053-020-09806-0

Shehata AA, Kassem AA, Brooks HL, Zuchuat V, Radwan AE (2021) Facies analysis and sequence-stratigraphic control on reservoir architecture: Example from mixed carbonate/siliciclastic sediments of Raha Formation, Gulf of Suez, Egypt. Marine Pet Geol $131: 105160$

Wang Y, Xian B (2006) Fault structures of northern steep slope zones and their influences on sedimentation and reservoir formation in Chezhen Sag. Pet Geol Recov Efficiency 13(6):5-8

Wang J, Zhang J, Xie J (2014) Fang, D: Initial gas full-component simulation experiment of Ban-876 underground gas storage. J Nat Gas Sci Eng 18:131-136

Wang J, Xie J, Lu H (2016) CO2 miscible flooding influence degree analysis of reservoir heterogeneity in low permeability reservoir. Int J Oil Gas Coal Technol 13(2):142-158

Wang J, Zhang Y, Xie J (2020) Influencing factors and application prospects of $\mathrm{CO} 2$ flooding in heterogeneous glutenite reservoirs. Sci Rep 10(1):1839

Wang J, Chen S, Jiang Z (2005) Sedimentary facies of the second and third members of Shahejie Formation in Chezhen Sag: Shengli Oilfield. Sedim Geol Tethyan Geol 25(3):1-2

Wang J, Xu Shu, Ji J, Yu J, Su C (2008) Identification Identification of gravel rock mass and reservoir physical properties prediction in steep slope zone of northern Chezhen depression. Marine Geol Quatern Geol 28(2):94-97

Xian B, Wang Y, Zhou T (2007) Distribution and controlling factors of glutinite bodies in the arctic region of a rift basin: an example from Chezhen Sag, Bohai Bay Basin. Pet Explor Dev 34(4):429-436

Xian B (2005) Study on sedimentary dynamic mechanism and reservoir distribution of steep slope zone in northern Chezhen Sag. Dongying: Postdoctoral Research Station of Shengli Oilfield

Zhao Z, Liu M (1984) The sublacustrine fan model and its application in oil and gas prediction. East China Pet Inst 4:323

Zhou T, Xian B, Lin H, Fan Z (2007) Sedimentary rules and reservoir characteristics of sublacustrine fan in Paleogene in steep slope of Chezhen Sag. Pet Geol Recov Efficiency. 14(2):23

Publisher's Note Springer Nature remains neutral with regard to jurisdictional claims in published maps and institutional affiliations. 